NASA/TM-2003-212110

\title{
Computation of Pressurized Gas Bearings Using CE/SE Method
}

Sorin Cioc, Florin Dimofte, and Theo G. Keith, Ir.

University of Toledo, Toledo, Ohio

David P. Fleming

Glenn Research Center, Cleveland, Ohio 
Since its founding, NASA has been dedicated to the advancement of aeronautics and space science. The NASA Scientific and Technical Information (STI) Program Office plays a key part in helping NASA maintain this important role.

The NASA STI Program Office is operated by Langley Research Center, the Lead Center for NASA's scientific and technical information. The NASA STI Program Office provides access to the NASA STI Database, the largest collection of aeronautical and space science STI in the world. The Program Office is also NASA's institutional mechanism for disseminating the results of its research and development activities. These results are published by NASA in the NASA STI Report Series, which includes the following report types:

- TECHNICAL PUBLICATION. Reports of completed research or a major significant phase of research that present the results of NASA programs and include extensive data or theoretical analysis. Includes compilations of significant scientific and technical data and information deemed to be of continuing reference value. NASA's counterpart of peerreviewed formal professional papers but has less stringent limitations on manuscript length and extent of graphic presentations.

- TECHNICAL MEMORANDUM. Scientific and technical findings that are preliminary or of specialized interest, e.g., quick release reports, working papers, and bibliographies that contain minimal annotation. Does not contain extensive analysis.

- CONTRACTOR REPORT. Scientific and technical findings by NASA-sponsored contractors and grantees.
- CONFERENCE PUBLICATION. Collected papers from scientific and technical conferences, symposia, seminars, or other meetings sponsored or cosponsored by NASA.

- SPECIAL PUBLICATION. Scientific, technical, or historical information from NASA programs, projects, and missions, often concerned with subjects having substantial public interest.

- TECHNICAL TRANSLATION. Englishlanguage translations of foreign scientific and technical material pertinent to NASA's mission.

Specialized services that complement the STI Program Office's diverse offerings include creating custom thesauri, building customized databases, organizing and publishing research results ... even providing videos.

For more information about the NASA STI Program Office, see the following:

- Access the NASA STI Program Home Page at http://wwzo.sti.nasa.gov

- E-mail your question via the Internet to help@stinasa.gov

- Fax your question to the NASA Access Help Desk at 301-621-0134

- Telephone the NASA Access Help Desk at 301-621-0390

- Write to: NASA Access Help Desk NASA Center for AeroSpace Information 7121 Standard Drive Hanover, MD 21076 
NASA/TM-2003-212110

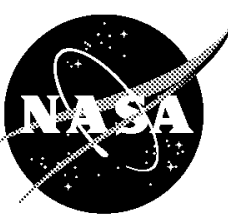

\section{Computation of Pressurized Gas Bearings Using CE/SE Method}

Sorin Cioc, Florin Dimofte, and Theo G. Keith, Ir.

University of Toledo, Toledo, Ohio

David P. Fleming

Glenn Research Center, Cleveland, Ohio

Prepared for the

2002 Annual Meeting

sponsored by the Society of Tribologists and Lubrication Engineers

Houston, Texas, May 19-23, 2002

National Aeronautics and

Space Administration

Glenn Research Center 
Available from

NASA Center for Aerospace Information 7121 Standard Drive

Hanover, MD 21076
National Technical Information Service 5285 Port Royal Road Springfield, VA 22100

Available electronically at http://glrs.grcnasa.gov 


\title{
Computation of Pressurized Gas Bearings Using CE/SE Method
}

\author{
Sorin Cioc, Florin Dimofte, and Theo G. Keith, Jr. \\ University of Toledo \\ Toledo, Ohio 43606 \\ David P. Fleming \\ National Aeronautics and Space Administration \\ Glenn Research Center \\ Cleveland, Ohio 44135
}

The space-time conservation element and solution element (CE/SE) method is extended to compute compressible viscous flows in pressurized thin fluid films. This numerical scheme has previously been used successfully to solve a wide variety of compressible flow problems, including flows with large and small discontinuities. In this paper, the method is applied to calculate the pressure distribution in a hybrid gas journal bearing. The formulation of the problem is presented, including the modeling of the feeding system. The numerical results obtained are compared with experimental data. Good agreement between the computed results and the test data were obtained, and thus validate the $\mathrm{CE} / \mathrm{SE}$ method to solve such problems.

\section{NOMENCLATURE}

$\begin{array}{ll}a & \text { Radius of feeding orifice } \\ a_{F}, b_{F}, c_{F} & \text { Coefficients in Taylor series expression of function } f \\ a_{G}, b_{G}, c_{G} & \text { Coefficients in Taylor series expression of function } g \\ C & \text { Radial clearance } \\ D & \text { Diameter of feeding pocket } \\ e & \text { Eccentricity } \\ \vec{F} & \overrightarrow{f i}+g \vec{k} \text { Vector flux term } \\ f & \text { ircumferential flux term, see Eq. (5) } \\ g & \text { Axial flux term, see Eq. (5) } \\ h & \text { Film thickness (dimensional) } \\ \bar{h} & h / C \text { Non-dimensional film thickness } \\ \vec{i}, \vec{k} & \text { unit vectors in circumferential and in axial directions, respectively } \\ L & \text { Length of bearing } \\ n & \text { Adiabatic coefficient } \\ n_{w} & \text { Number of waves (for wave bearings) } \\ n s & \text { Number of feeding holes } \\ p & \text { Fluid pressure } \\ \bar{p} & p / p_{0} \text { Non-dimensional pressure } \\ p_{0} & \text { Atmospheric (reference) pressure } \\ p_{s} & \text { Supply pressure } \\ Q & \text { Mass flow rate through one feeding hole } \\ \bar{Q} & \text { Non-dimensional mass flow rate through one feeding hole (see Eq. (17)) } \\ R & \text { Journal bearing radius } \\ & \end{array}$




$\begin{array}{ll}t & \text { Time } \\ \bar{t} & t \frac{p_{0}}{\mu}\left(\frac{C}{R}\right)^{2} \text { Non-dimensional time } \\ u & \bar{h} \bar{\rho} \text { Dependent variable in governing equation } \\ U & \omega R \text { Velocity in circumferential direction } \\ \bar{U} & \frac{\mu \omega}{2 \pi p_{0}}\left(\frac{R}{C}\right)^{2} \text { Non-dimensional circumferential velocity } \\ x & \text { Circumferential coordinate } \\ \bar{x} & x /(2 \pi R) \text { Non-dimensional circumferential coordinate } \\ \bar{x}_{0} & \text { Position of maximum film thickness, measured in negative direction of axis } \bar{x} \\ \bar{x} & \text { Position of wave peak (for wave bearings), measured in negative direction of axis } \bar{x} \\ z & \text { Axial coordinate } \\ \bar{z} & z /(2 \pi R) \text { Non-dimensional axial coordinate } \\ \gamma & \text { Isentropic exponent; } \gamma=1.405 \text { for air } \\ \Delta x & \text { Grid spacing in longitudinal direction } \\ \Delta t & \text { Time step } \\ \varepsilon & \text { Weight parameter characterizing one form of artificial dissipation, or } \\ & e / C \text { Eccentricity ratio } \\ \varepsilon_{w} & \text { Wave amplitude (for wave bearings) } \\ \mu & \text { Fluid viscosity } \\ \rho & \text { Fluid density } \\ \bar{\rho} & \rho / \rho_{0} \text { Non-dimensional fluid density } \\ \rho_{0} & \text { Atmospheric (reference) density } \\ \omega & \text { Angular velocity of the journal bearing } \\ & \end{array}$

Subscripts and superscripts, other than shown above

( ) Value of the variable at the point $\mathrm{O}$

( ) Supply pocket index

()$_{x},()_{z},()_{t}$ Partial derivative with respect to $x, z$, and $t$, respectively

()$^{n} \quad$ Time step

\section{INTRODUCTION}

Gas lubrication, though preceded by occasional experimental work since the mid $19^{\text {th }}$ century, experienced a strong development in the "Golden Era" of gas lubrication, which started in the last years of World War II, and ended in the first part of the 1970's (Pan, 1990). In this period much important work was published: Fuller (1956), Lund (1964, 1967), Castelli and Pirvics (1968), Constantinescu (1969). More recently, significant advancements were reported in gas film modeling including rarefaction effects (Wu and Bogy, 2001), in numerical methods applicable to high-speed bearings (Faria and San Andrés, 2000), and particularly in the treatment of complex geometries, including discontinuities (Bonneau, Huitric and Tournerie, 1993). 
The space-time conservation element and solution element (CE/SE) method was proposed by Chang and To (1991). Over the past several years it has been utilized in a number of fluid flow applications that involve shock waves, contact discontinuities, acoustic waves, vortices and chemical reactions. One of its main features is that it can simultaneously capture small and large discontinuities (such as sound waves and shock waves) without introducing numerical oscillations into the solution, as shown by Chang, Wang, and Chow (1999), and Chang et al. (1998).

Compressible viscous flow in pressurized thin fluid films, with application in hybrid gas bearings, can encounter large pressure gradients due to the feeding system or to the large peripheral velocities of the bearing. In these conditions, the computational methods based on standard finite difference methods or classic finite volume methods may prove inadequate, having convergence problems or inducing oscillations into the solution. Thus, a method that is conceptually simple, is second order accurate for the entire domain, and is able to naturally deal with large gradients and/or discontinuities in the solutions without introducing numerical oscillations or smearing, is welcome.

\section{ANALYSIS}

The two-dimensional, transient, Reynolds equation, written for a Newtonian compressible fluid in laminar flow is,

$$
\frac{\partial \rho h}{\partial t}+\frac{\partial}{\partial x}\left(\frac{\rho h U}{2}-\frac{\rho h^{3}}{12 \mu} \frac{\partial p}{\partial x}\right)+\frac{\partial}{\partial z}\left(-\frac{\rho h^{3}}{12 \mu} \frac{\partial p}{\partial z}\right)=0
$$

The flow is considered polytropic, i.e.,

$$
\frac{p}{\rho^{n}}=\text { const. }
$$

where the polytropic exponent $n=1$ for isothermal flow, $n=1.405$ for adiabatic flow, or can have other values for general polytropic flows.

A more suitable form of the Reynolds equation for numerical formulation is obtained using a new variable $u$ that is the product of the non-dimensional film thickness and the pressure, i.e.,

$$
u=\bar{h} \bar{\rho}
$$

In terms of $u$, in non-dimensional variables, the Reynolds equation can be written as

$$
\frac{\partial u}{\partial \bar{t}}+\frac{\partial f}{\partial \bar{x}}+\frac{\partial g}{\partial \bar{z}}=0
$$

where the flux terms $f$ and $g$ are, 


$$
\begin{aligned}
& f=\frac{u \bar{U}}{2}-\frac{n u^{n}}{48 \pi^{2} \bar{h}^{n-1}}\left(u_{x} \bar{h}-u \bar{h}_{x}\right), \\
& g=-\frac{n u^{n}}{48 \pi^{2} \bar{h}^{n-1}}\left(u_{z} \bar{h}-u \bar{h}_{z}\right) .
\end{aligned}
$$

All partial derivatives considered in Eqs. (4) and (5) are carried out relative to non-dimensional variables $\bar{t}, \bar{x}, \bar{z}$. In the following, in order to simplify the expressions, the non-dimensional notation (upper bar) will be dropped, and all variables will be implicitly considered in non-dimensional form.

Consider a triangular mesh that covers the $(x, z)$ spatial domain. One triangle $B C D$ and its three neighboring elements are shown in Fig. 1. Point $A$ is the centroid of the triangle $B C D$, while points $E, F$ and $G$ are the centroids of the neighboring triangles $B C H, C D I$ and $B D J$, respectively. The CE/SE method calculates the values of the dependent variables $u, u_{x}, u_{z}$ for point $A$ at the time step $t=t^{n+\frac{1}{2}}$ using the corresponding values of the same variables for the points $E, F$ and $G$ at the time step $t=t^{n}$. In order to calculate the three unknowns at the new time step, a system of three equations will be derived.

Consider the quadrilateral $A B E C$. Simultaneously integrating Eq. (4) over the surface of this quadrilateral and in time, between time steps $t^{n}$ and $t^{n+\frac{1}{2}}$ (see Fig. 2), yields

$$
\iint_{A B E C} \int_{t^{n}}^{n+\frac{1}{2}} \frac{\partial u}{\partial t} \mathrm{~d} t \mathrm{~d} \sigma+\int_{t^{n}}^{t^{n+\frac{1}{2}}} \iint_{A B E C}\left[\frac{\partial f}{\partial x}+\frac{\partial g}{\partial z}\right] \mathrm{d} \sigma \mathrm{d} t=0 .
$$

Performing the time integration for the first term and transforming the surface integration into a contour integration for the second term (using Green's theorem) produces

$$
\iint_{A B E C}\left(u^{n+\frac{1}{2}}-u^{n}\right) \mathrm{d} \sigma+\int_{t^{n}}^{t^{n+\frac{1}{2}}} \oint_{A B E C} \vec{F} \cdot \vec{n} \mathrm{~d} s \mathrm{~d} t=0
$$

where $\vec{n}$ is the unit vector normal to the contour, oriented outwards and

$$
\vec{F}=f \vec{i}+g \vec{k}
$$

is the vector in the $(x, z)$ plane characterized by the Cartesian unit vectors $(\vec{i}, \vec{k})$. Functions $f$ and $g$ are given by Eq. (5). Equation (7) implies conservation of flux in the three-dimensional space $(x, z, t)$. Functions $u, f, g$ are next written with linear approximations using first order Taylor expansions, i.e.,

$$
\begin{gathered}
u \cong u_{0}+\left(u_{x}\right)_{0}\left(x-x_{0}\right)+\left(u_{z}\right)_{0}\left(z-z_{0}\right)+\left(u_{t}\right)_{0}\left(t-t_{0}\right), \\
f \cong f_{0}+\left(\frac{\partial f}{\partial u}\right)_{0}\left(u-u_{0}\right)+\left(\frac{\partial f}{\partial u_{x}}\right)_{0}\left[u_{x}-\left(u_{x}\right)_{0}\right]+\left(\frac{\partial f}{\partial u_{z}}\right)_{0}\left[u_{z}-\left(u_{z}\right)_{0}\right]=a_{F} u+b_{F} u_{x}+c_{F},
\end{gathered}
$$




$$
g \cong g_{0}+\left(\frac{\partial g}{\partial u}\right)_{0}\left(u-u_{0}\right)+\left(\frac{\partial g}{\partial u_{x}}\right)_{0}\left[u_{x}-\left(u_{x}\right)_{0}\right]+\left(\frac{\partial g}{\partial u_{z}}\right)_{0}\left[u_{z}-\left(u_{z}\right)_{0}\right]=a_{G} u+b_{G} u_{z}+c_{G}
$$

Substituting Eq. (9) into Eqs. (10) and (11) yields linear expressions for $f$ and $g$ as functions of $(x, z, t)$. In Eqs. (10) and (11), coefficients $a_{F}, b_{F}, c_{F}, a_{G}, b_{G}, c_{G}$ are considered constant when integrating Eq. (7), and are known as functions of $u_{0},\left(u_{x}\right)_{0},\left(u_{z}\right)_{0}$. In Eq. (9), the time derivative can be calculated as function of the space derivatives using Eq. (3), i.e.,

$\left(u_{t}\right)_{0}=-\left(f_{x}\right)_{0}-\left(g_{z}\right)_{0} \cong-a_{F}\left(u_{x}\right)_{0}-a_{G}\left(u_{z}\right)_{0}$.

Equations (8-12) are then substituted into Eq. (7). Point $\left(x_{A^{\prime}}, z_{A^{\prime}}, t^{n+\frac{1}{2}}\right)$ is used as the Taylor expansion point for the expressions of $u^{n+\frac{1}{2}}, f$ and $g$ on the contour segments $A B$ and $C A$, while point $\left(x_{E^{\prime}}, z_{E^{\prime}}, t^{n}\right)$ is used as the Taylor expansion point for the expressions of $u^{n}, f$ and $g$ on the contour segments $B E$ and $E C$. Thus, a first equation with three unknowns, the values $u, u_{x}, u_{z}$ at the new half time step $\left(x_{A^{\prime}}, z_{A^{\prime}}, t^{n+\frac{1}{2}}\right)$, is obtained. The coordinates of points $A^{\prime}$ and $E^{\prime}$ are selected in a suitable way, as will be shown later. The equation is linear and has the general form

$$
a_{1} u_{A^{\prime}}^{n+\frac{1}{2}}+b_{1}\left(u_{x}\right)_{A^{\prime}}^{n+\frac{1}{2}}+c_{1}\left(u_{z}\right)_{A^{\prime}}^{n+\frac{1}{2}}+d_{1} u_{E^{\prime}}^{n}+e_{1}\left(u_{x}\right)_{E^{\prime}}^{n}+f_{1}\left(u_{z}\right)_{E^{\prime}}^{n}+g_{1}=0
$$

Two other similar equations are obtained using the same procedure for the conservation elements $A C F D$ and $A D G B$. These equations have the general form

$$
\begin{aligned}
& a_{2} u_{A^{\prime}}^{n+\frac{1}{2}}+b_{2}\left(u_{x}\right)_{A^{\prime}}^{n+\frac{1}{2}}+c_{2}\left(u_{z}\right)_{A^{\prime}}^{n+\frac{1}{2}}+d_{2} u_{F^{\prime}}^{n}+e_{2}\left(u_{x}\right)_{F^{\prime}}^{n}+f_{2}\left(u_{z}\right)_{F^{\prime}}^{n}+g_{2}=0, \\
& a_{3} u_{A^{\prime}}^{n+\frac{1}{2}}+b_{3}\left(u_{x}\right)_{A^{\prime}}^{n+\frac{1}{2}}+c_{3}\left(u_{z}\right)_{A^{\prime}}^{n+\frac{1}{2}}+d_{3} u_{G^{\prime}}^{n}+e_{3}\left(u_{x}\right)_{G^{\prime}}^{n}+f_{3}\left(u_{z}\right)_{G^{\prime}}^{n}+g_{3}=0 .
\end{aligned}
$$

The linearized system formed by Eqs. (13a), (13b), and (13c) can be solved using an iterative method; note that the coefficients $a_{i}, b_{i}, c_{i}, i=1,2,3$ are functions of the unknowns $u_{A^{\prime}}^{n+\frac{1}{2}},\left(u_{x}\right)_{A^{\prime}}^{n+\frac{1}{2}},\left(u_{z}\right)_{A^{\prime}}^{n+\frac{1}{2}}$. An alternate approach is to choose the Taylor series expansion point $A^{\prime}$ as the center of the hexagon $B E C F D G$. The other three Taylor series expansion points $E^{\prime}, F^{\prime}, G^{\prime}$ can be chosen arbitrarily; however, in order to maintain consistency, they are selected as the centers of the corresponding hexagons formed around the neighboring triangular elements.

Adding Eqs. (13a), (13b), and (13c) yields a new equation that represents the flux conservation over the hexagon and over one half time step. When point $A^{\prime}$ is the centroid of the hexagon $B E C F D G$, this equation has a simpler form given by 


$$
\begin{gathered}
a_{s u m} u_{A^{\prime}}^{n+\frac{1}{2}}+d_{1} u_{E^{\prime}}^{n}+e_{1}\left(u_{x}\right)_{E^{\prime}}^{n}+f_{1}\left(u_{z}\right)_{E^{\prime}}^{n}+d_{2} u_{F^{\prime}}^{n}+e_{2}\left(u_{x}\right)_{F^{\prime}}^{n}+f_{2}\left(u_{z}\right)_{F^{\prime}}^{n} \\
d_{3} u_{G^{\prime}}^{n}+e_{3}\left(u_{x}\right)_{G^{\prime}}^{n}+f_{3}\left(u_{z}\right)_{G^{\prime}}^{n}+g_{s u m}=0,
\end{gathered}
$$

where $a_{\text {sum }}$ is given by

$$
a_{\text {sum }}=A_{A B E C}+A_{A C F D}+A_{A D G B}=A_{B E C F D G} .
$$

Equation (14) has only one unknown, $u_{A^{\prime}}^{n+\frac{1}{2}}$, and can easily be solved explicitly. It is also important to note that all the coefficients in Eq. (14) depend only on the geometry (coordinates of the points) and the values of the dependent variables at the previous half time step so that an iterative method is not needed. After calculating the value $u_{A^{\prime}}^{n+\frac{1}{2}}$, the values of the other two dependent variables $\left(u_{x}\right)_{A^{\prime}}^{n+\frac{1}{2}}$ and $\left(u_{z}\right)_{A^{\prime}}^{n+\frac{1}{2}}$ can be calculated using any two of the Eqs. (13a), (13b), and (13c). This is also called the $a$ scheme.

Note that the $a$ scheme introduces "no significant damping" (Chang, Wang, \& Chow, 1999; Chang et al., 1998), so that some form of artificial dissipation is generally necessary. The scheme can be simplified and simultaneously stabilized by calculating the space derivatives in a different way. The scheme thus obtained is called the $a-\varepsilon-\alpha-\beta$ scheme. In this scheme, the derivatives are calculated as weighted averages between the derivatives calculated from the governing equations, as shown above (the $a$ scheme), the derivatives calculated using 2-D central difference finite difference formulae (weight parameter $\varepsilon$ ) and the derivatives using 2-D side finite differencing (weight parameter $\beta$ ). Parameter $\alpha$ is the power index used in the computation of the non-linear weighted average that employs 2-D side finite differencing. The complete formulation of the way the derivatives are calculated in the $a-\varepsilon-\alpha-\beta$ scheme can be found in Chang et al. (1998). It is important that, for a certain value of the weighting parameter $\varepsilon(\varepsilon=0.5)$, the $a-\varepsilon-\alpha-\beta$ scheme eliminates the necessity of calculating the space derivatives from the governing equations, thus the method becomes purely explicit.

The feed system, formed by a number $n s$ of orifices with the general geometry shown in Fig. 3, can be modeled using a generally accepted formula (Lund, 1964, 1967), that links the mass flow ratio to the feed system geometry and the pressures at the ends of the feed system considering both effects of the orifice restrictor and the inherent restrictor, i.e.,

$$
Q=\frac{\pi a^{2} \sqrt{p_{s} \rho_{s}}}{\sqrt{1+\left(\frac{a^{2}}{d h}\right)^{2}}} \bar{Q}
$$

where the non-dimensional mass flow $\bar{Q}$ is a fraction $C_{D}$ of the ideal mass flow, 


$$
\bar{Q}=C_{D}\left\{\begin{array}{cc}
\sqrt{\left(\frac{2}{\gamma+1}\right)^{\frac{\gamma+1}{\gamma-1}}} & \text { for } \frac{p_{i}}{p_{s}} \leq\left(\frac{2}{\gamma+1}\right)^{\frac{\gamma}{\gamma-1}}, \\
\sqrt{\frac{2 \gamma}{\gamma-1}\left(\frac{p_{i}}{p_{s}}\right)^{\frac{2}{\gamma}}\left[1-\left(\frac{p_{i}}{p_{s}}\right)^{\frac{\gamma-1}{\gamma}}\right]} & \text { for }\left(\frac{2}{\gamma+1}\right)^{\frac{\gamma}{\gamma-1}}<\frac{p_{i}}{p_{s}} \leq 1 .
\end{array}\right.
$$

When no restricting orifice is present (i.e., an inherent restrictor), Eq. (16) becomes

$$
Q=\pi d h \sqrt{p_{s} \rho_{s}} \bar{Q}
$$

The feeding system is introduced into the bearing computation through the boundary conditions. Thus, on each feeding pocket contour, the mass flow rates calculated from the bearing equations and from the feeding system, respectively, must be equal

$$
\left(Q_{i}\right)_{\text {bearing }}=\left(Q_{i}\right)_{\text {feeding }}, i=1,2, \cdots, n s \text {. }
$$

Equation (19) represents a nonlinear set of $n s$ equations, where the pressures in the bearing at the feeding holes are the unknowns $p_{i}, i=1,2, \cdots, n s$. This system is solved iteratively using Newton's method

\section{RESULTS AND DISCUSSION}

A computer code has been developed based on the described method, using the $a-\varepsilon-\alpha-\beta$ scheme with $\varepsilon=0.5$. This code has been tested for some simple cases where experimental data were available, considering isothermal flow $(n=1)$.

The first case considered was the circular gas bearing without any feeding system. The results are shown in Fig. 4, where the same bearing with aspect ratio $L /(2 R)=2.0$ is examined for two bearing

numbers $\Lambda=\left(6 \mu \omega R^{2}\right) /\left(p_{0} C^{2}\right)$ and for two eccentricities. There are no significant differences between the experimental and calculated pressure distributions, at least in the middle plane where the experimental results are available. The relative differences between the experimental and calculated non-dimensional loads $\zeta=L o a d /\left(p_{0} 2 L R\right)$ are $3.5 \%$ and $4.0 \%$; both represent improvements over the theoretical results shown by Constantinescu (1969).

The second case considered is the wave journal bearing (Dimofte, 1995) without any feed system. The fluid film thickness in an aligned wave bearing is given as

$$
\bar{h}=1+\varepsilon \cos 2 \pi\left(\bar{x}+\bar{x}_{0}\right)+\varepsilon_{w} \cos \left[2 \pi n_{w}\left(\bar{x}+\bar{x}_{w}\right)\right] .
$$

In the last term on the right hand side of Eq. (19), $\varepsilon_{w}$ is the wave amplitude, $n_{w}$ is the number of waves and $x_{w}$ is the wave origin relative to the origin of the $\bar{x}$ axis. For the present case, the bearing diameter 
and bearing length are $50 \mathrm{~mm}$, the radial clearance is $0.02 \mathrm{~mm}, n_{w}=3, \varepsilon_{w}=0.3$, and the relative minimum film thickness is $\bar{h}_{\text {min }}=0.3$ for all cases. The bearing number $\Lambda$ is 3.566 .

The results are compared with a finite difference based code built by Dimofte (1995). Different bearing positions $\left(x_{w}\right)$ have been tested and the results (calculated load magnitude and position) are presented in Table 1. The results show very good agreement between the two methods.

The third case considered is a pressurized gas bearing without rotation and with zero eccentricity. Details of the bearing geometry and working conditions are presented in Table 2. Figures 5a and $5 \mathrm{~b}$ show the calculated and experimental pressure distributions for two values of the radial clearance, corresponding to the subsonic flow regime (obtained when $C=12.7 \mu \mathrm{m}$ ), and the choked flow regime (obtained when $C=31.75 \mu \mathrm{m}$ ) in the feed system, in two longitudinal planes situated at the jet position (Fig. 5a) and at half distance between jets (Fig. 5b). Pressure peaks are visible at the jet positions; also nearly constant pressure is obtained between the supply planes. The predicted pressure peaks at the position of jet are higher than the experimental values (this difference is more visible for subsonic inlet flow, however it is present in both cases). This is due to the difficulty of measuring the local pressure at the feeding orifice position. The value for the correction factor $C_{D}$ is 0.8 for subsonic inlet flow, and 0.85 for choked flow.

Finally, the code was applied to different configurations where experimental or computed data were not available.

Figure 6 shows the pressure distribution (sections at the jet and at the mid-jet positions) obtained for five supply planes for the same bearing as in the previous case for $C=12.7 \mu \mathrm{m}$. The supply planes are equally distanced with respect to each other and with the bearing ends. It is seen that, although the external pressure is the same for all supply holes, the pressure that develops in the pockets (inside the bearing) is not the same for all supply planes. The pressure distribution between two consecutive feeding planes has an almost linear form. Furthermore, at the central supply plane, the peak pressures are not as prominent as the peak pressures at the other supply planes. This suggests that the central supply plane does not have an important contribution for the general pressure distribution inside the bearing.

Figure 7 shows the pressure distribution in a half bearing for the same bearing geometry as in the previous two cases, but in a running condition $(40,000 \mathrm{rpm}, \Lambda=25.76)$, with a relative eccentricity $\varepsilon=0.5$. The value $C_{D}=0.8$ was used. The pressure distribution is very complex. It can be seen that for many feeding holes the flow is inverted, i.e., is directed from the bearing towards the feeding system, because the pressure inside the bearing is higher than the supply pressure.

\section{CONCLUSIONS}

The CE/SE computational method has been extended for the first time to calculate compressible viscous flow in pressurized thin fluid films with restrictors in series. Formulation of the method was presented along with numerical results obtained for both non-pressurized and pressurized bearings. The results were compared with existing experimental and computed data. The results demonstrate the ability of the method to accurately predict pressure distribution in such flows.

While most numerical methods handle space and time differencing terms in the governing equations separately, this relatively new scheme treats them in a unified way. This results in very good 
accuracy even though the unknowns are considered locally linear and even when a relatively course grid is used. Also, the entire structure of the method, as well as the developed code, is relatively simple. Unlike most numerical schemes, no special treatment is necessary for discontinuities, providing that the governing equations are written in strong conservative form. However, the method is limited to time dependent equations. Steady state results, such as those discussed in this work, can be obtained only after the stabilization of the unsteady solution starting from initial conditions.

Future work will focus on predicting dynamic characteristics of pressurized gas bearings. Improving the feeding system with restrictors in series modeling will also be considered, as well as improving the computation time. Cases including discontinuities will also be considered.

\section{REFERENCES}

Bonneau, D., Huitric, J., Tournerie, B., (1993), "Finite Element Analysis of Grooved Gas Thrust Bearings and Grooved Gas Face Seals", J. of Tribology, Trans. ASME, 115, 3, pp 348-354.

Castelli, V., Pirvics, J., (1968), "Review of Numerical Methods in Gas Bearing Film Analysis", $J$. of Lubrication Technology, Trans ASME, vol. 90, October, pp. 777-792.

Chang, S.C., To, W.M., (1991), “A New Numerical Framework for Solving Conservation Laws The Method of Space-Time Conservation Element and Solution Element", NASA TM-104495, NASA, Cleveland, $\mathrm{OH}$.

Chang, S.C., et al., (1998), "Fundamentals of CE/SE method", NASA/TM-1998-208843, PDF file http:/www.grc.nasa.gov/WWW/microbus/cese/ltxjcp2d.pdf, Cleveland, $\mathrm{OH}$.

Chang, S.C., Wang, X.Y., Chow, C.Y., (1999), "The Space-Time Conservation Element and Solution Element Method: A New High-Resolution and Genuinely Multidimensional Paradigm for solving Conservation Laws", J. of Comp. Phys., 156, 1, pp. 89-136.

Constantinescu, V.N., (1969), "Gas Lubrication", American Society of Mechanical Engineers, Ed. Robert L. Wehe, New York, pp. 455-467.

Dimofte, F., (1995), "Wave Journal Bearing with Compressible Lubricant; Part I: The Wave Bearing Concept and a Comparison to the Plain Circular Bearing", STLE Tribology Trans., Vol. 38, 1, pp. 153-160.

Faria, M.T.C, San Andrés, L., (2000), “On the Numerical Modeling of High-Speed Hydrodynamic Gas Bearings", Trans. ASME, vol. 122, 1, pp. 124-130.

Fuller, D.D., (1956, 1984), “Theory and Practice of Lubrication for Engineers”, New York, Wiley.

Lund, J.W., (1964), "The Hydrostatic Gas Journal Bearing With Journal Rotation and Vibration", J. of Basic Engineering, Trans. ASME, vol. 86, June, pp. 328-336. 
Lund, J.W., (1967), "A Theoretical Analysis of Whirl Instability and Pneumatic Hammer for a Rigid Rotor in Pressurized Gas Journal Bearings", J. of Lubrication Technology, Trans. ASME, vol. 89, April, pp. 328-336.

Pan, Coda H.T., (1990), "Gas Lubrication (1915-1990)", Achievements in Tribology: on the $75^{\text {th }}$ Anniversary of the ASME Research Committee on Tribology, Trib-Vol.1, pp. 31-55.

Wu, L., Bogy, D.B., (2001), "Numerical Simulation of the Slider Air Bearing Problem of Hard Disk Drives by Two Multidimensional Upwind Residual Distribution over Unstructured Triangular Meshes", J. of Computational Physics, 172, 2, pp. 640-657.

Table 1. - Comparison between calculated data with CE/SE method and with finite difference method

\begin{tabular}{|c|c|c|c|c|c||}
\hline Eccentricity & $\begin{array}{c}\alpha_{w} \\
(\mathbf{d e g})\end{array}$ & $\begin{array}{c}\text { Load CE/SE } \\
(\mathbf{N})\end{array}$ & $\begin{array}{c}\text { Load FD } \\
(\mathbf{N})\end{array}$ & $\begin{array}{c}\text { Load angle } \\
\text { CE/SE (deg) }\end{array}$ & $\begin{array}{c}\text { Load angle } \\
\text { FD (deg) }\end{array}$ \\
\hline 0.502 & 40 & 177 & 177 & 40.49 & 40.18 \\
\hline 0.460 & 32 & 170 & 170 & 39.09 & 38.8 \\
\hline 0.433 & 24 & 166 & 165 & 36.37 & 36.11 \\
\hline 0.416 & 16 & 163 & 162 & 32.94 & 32.69 \\
\hline 0.404 & 8 & 158 & 158 & 29.30 & 29.06 \\
\hline 0.400 & 0 & 154 & 154 & 25.61 & 25.38 \\
\hline 0.404 & -8 & 151 & 151 & 22.08 & 21.86 \\
\hline 0.416 & -16 & 149 & 148 & 18.95 & 18.75 \\
\hline
\end{tabular}

Table 2. - Pressurized gas bearing geometry and working conditions

\begin{tabular}{||c|c||}
\hline Bearing length $(\mathrm{mm})$ & 117.5 \\
\hline Bearing diameter $(\mathrm{mm})$ & 60.4 \\
\hline Supply planes & 2 \\
\hline Supply plane position $(\mathrm{mm})$ & 12.7 \\
\hline Holes/supply plane & 14 \\
\hline Orifice diameter $(\mathrm{mm})$ & 0.16 \\
\hline Pocket diameter $(\mathrm{mm})$ & 0.9 \\
\hline Supply pressure $(\mathrm{Pa})$ & $5.514 \times 10^{5}$ \\
\hline Injection angle $(\mathrm{deg})$ & 90 \\
\hline
\end{tabular}




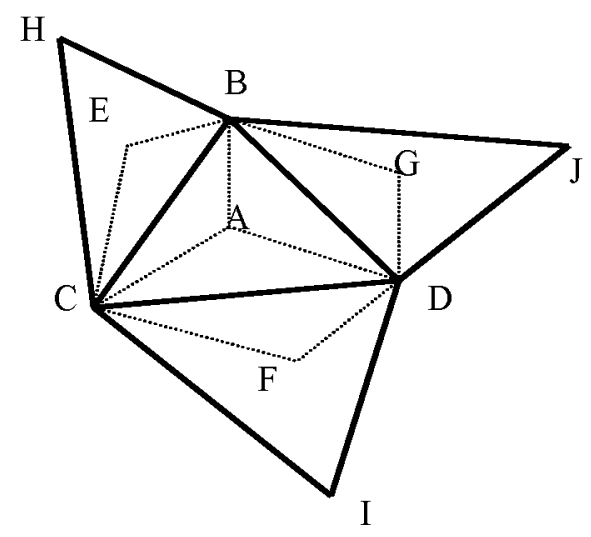

Fig. 1 - Triangular mesh element and its neighbors.

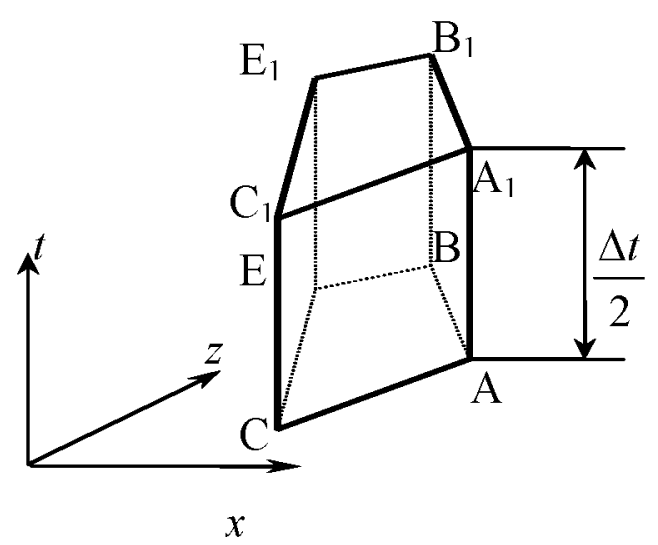

Fig. 2 - Conservation volume in $(x, z, t)$ space. 


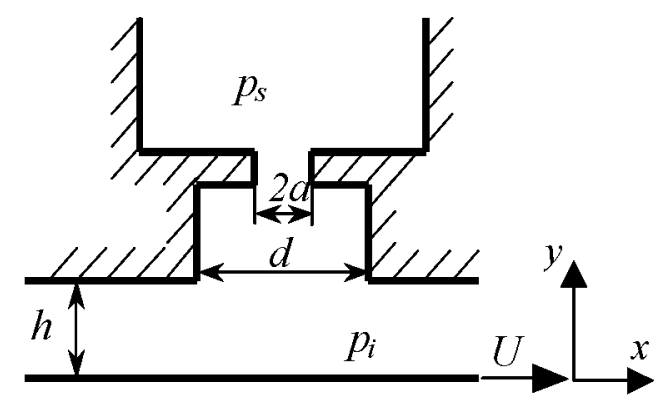

Fig. 3 - Feeding orifice geometry.

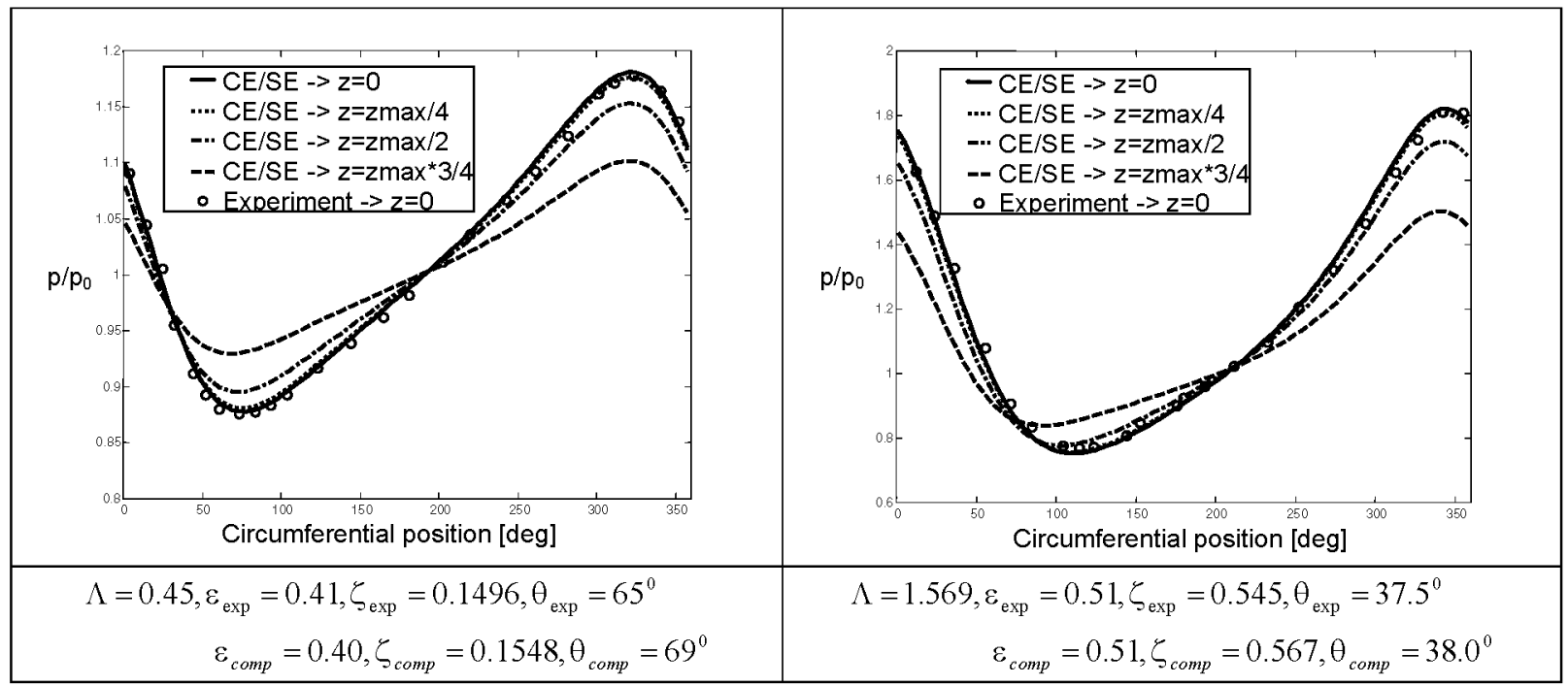

Fig. 4 - Comparison between numerical and experimental results for pressure distribution in gas journal bearing. 


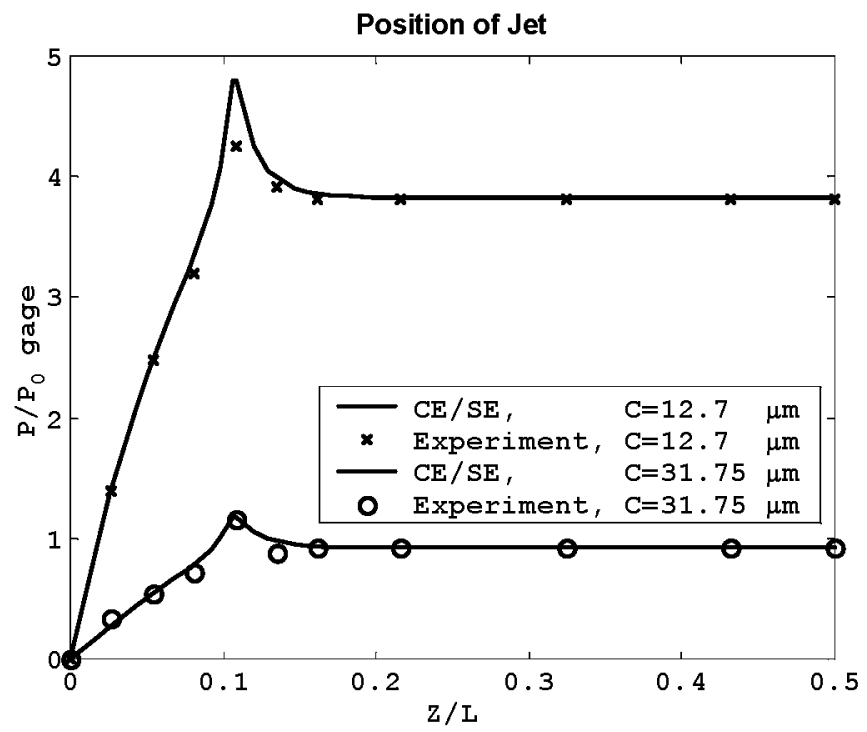

(a) Jet position.

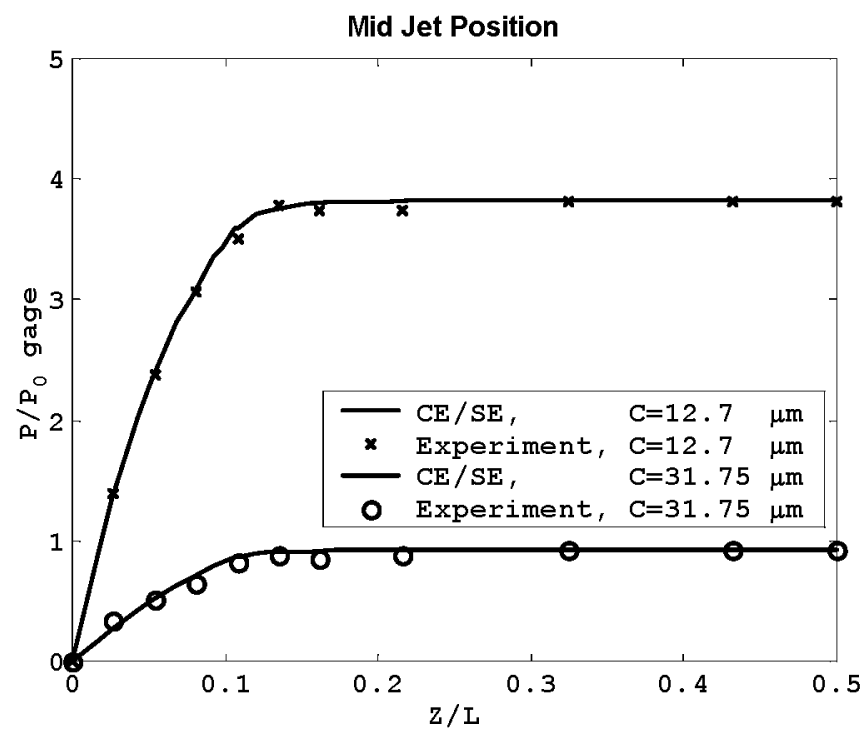

(b) Mid-jet position.

Fig. 5 - Comparison between calculated and experimental pressure distributions. 


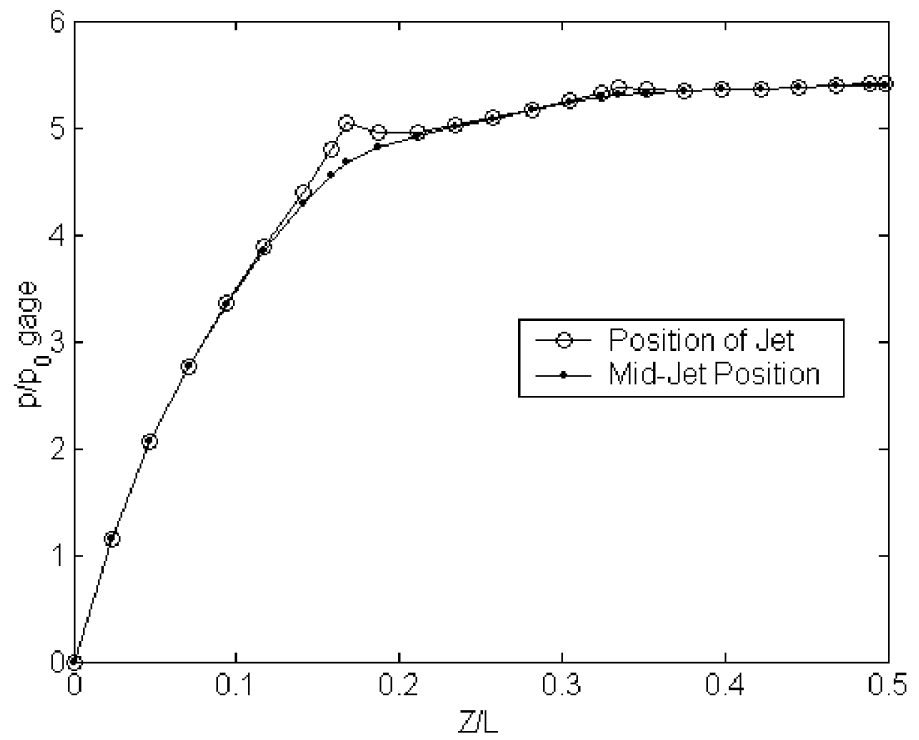

Fig. 6 - Pressure distribution for circular bearing without eccentricity; five supply planes.

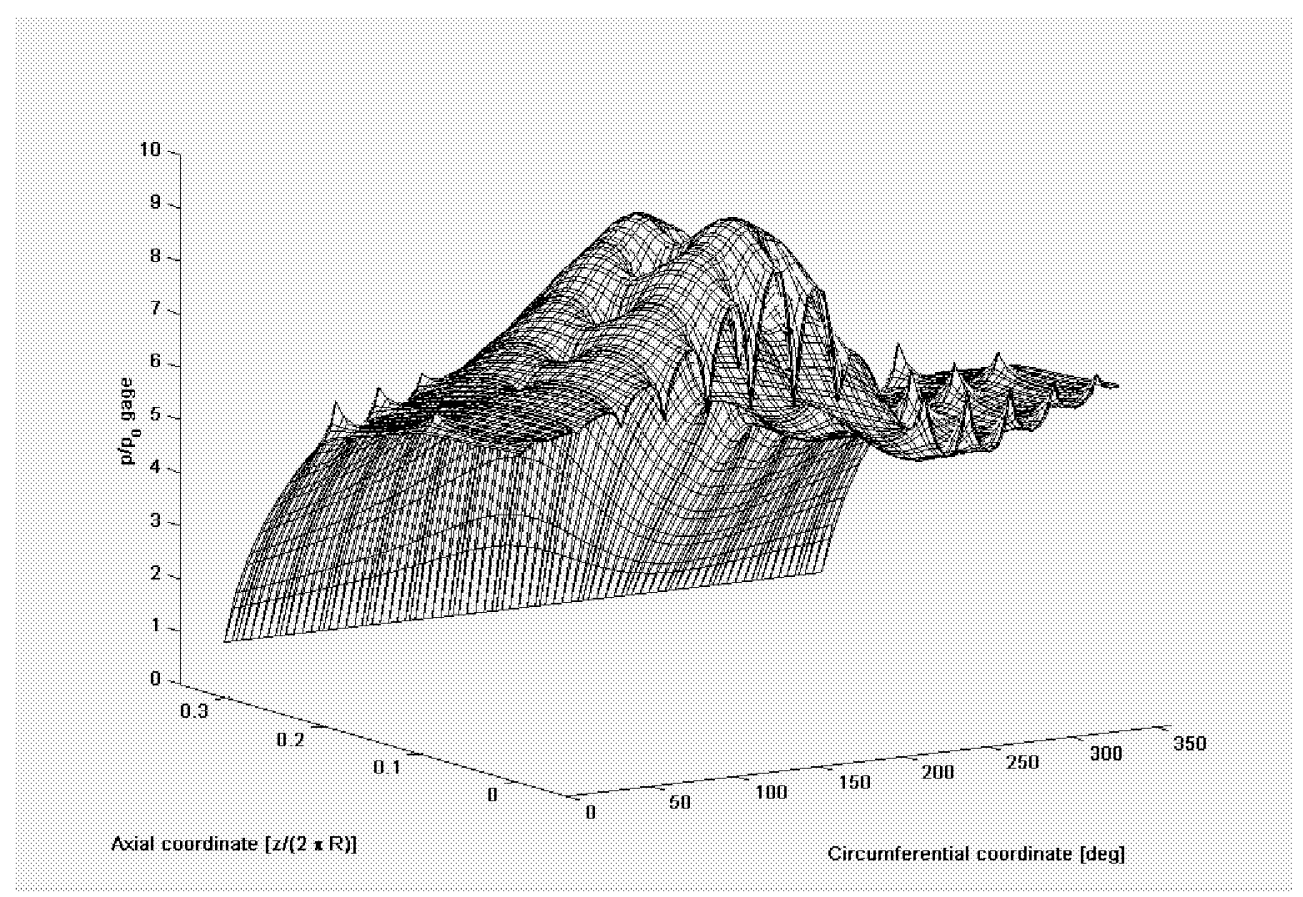

Fig. 7 - Pressure distribution for circular bearing with eccentricity; five supply planes. 


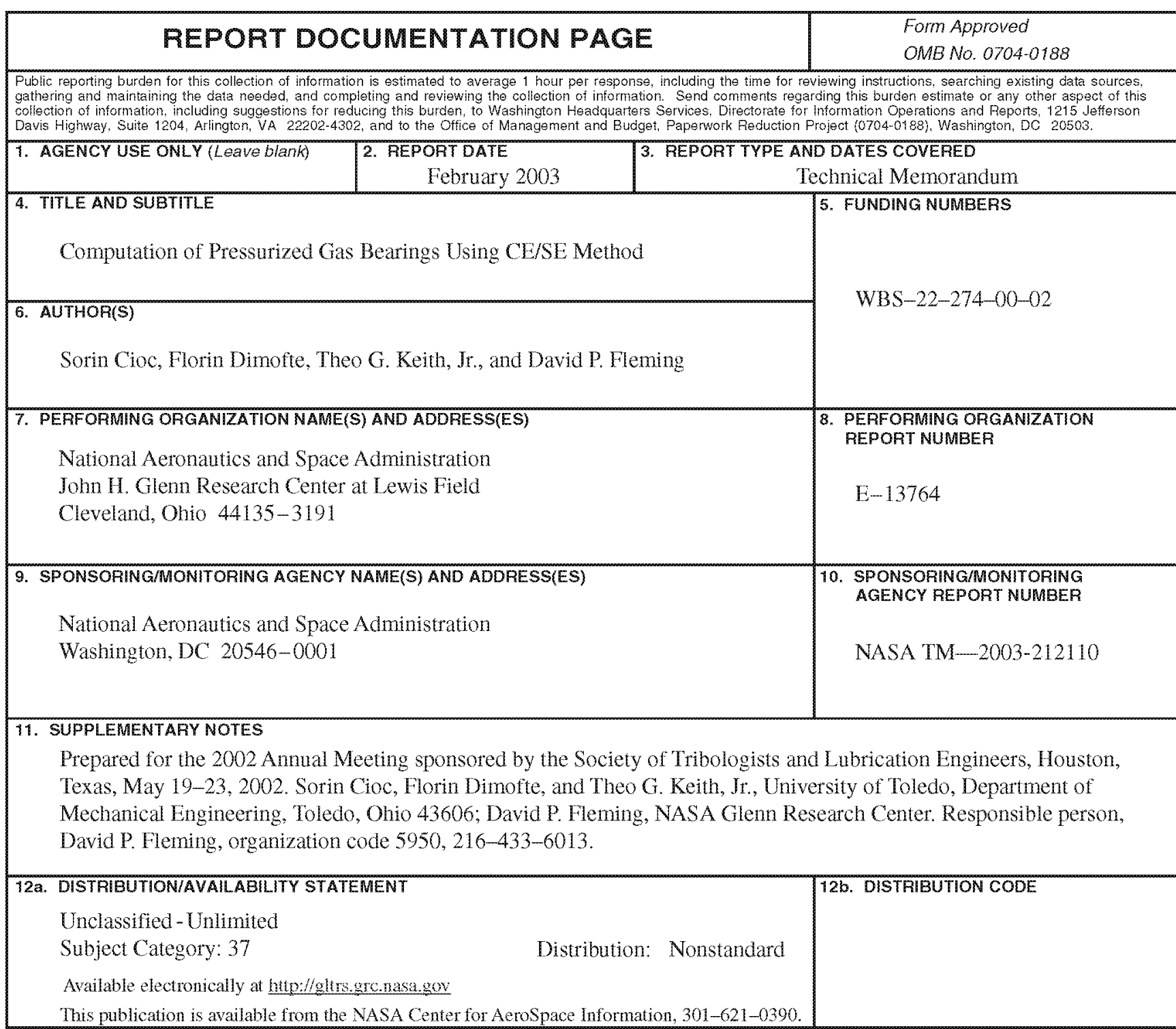

13. ABSTRACT (Maximum 200 words)

The space-time conservation element and solution element (CE/SE) method is extended to compute compressible viscous flows in pressurized thin fluid films. This numerical scheme has previously been used successfully to solve a wide variety of compressible flow problems, including flows with large and small discontinuitites. In this paper, the method is applied to calculate the pressure distribution in a hybrid gas journal bearing. The formulation of the problem is presented, including the modeling of the feeding system. the numerical results obtained are compared with experimental data. Good agreement between the computed results and the test data were obtained, and thus validate the CE/SE method to solve such problems.

\begin{tabular}{|c|c|c|c|}
\hline \multirow{2}{*}{\multicolumn{3}{|c|}{$\begin{array}{l}\text { 14. SUBJECT TERMS } \\
\text { Bearings; Gas; Hydrostatic lubrication; Flow rate }\end{array}$}} & \multirow{3}{*}{$\begin{array}{l}\text { 15. NUMBER OF PAGES } \\
20 \\
\text { 16. PRICE CODE } \\
\end{array}$} \\
\hline & & & \\
\hline $\begin{array}{l}\text { 17. SECURITY CLASSIFICATION } \\
\text { OF REPORT } \\
\text { Unclassified }\end{array}$ & $\begin{array}{l}\text { 18. SECURITY CLASSIFICATION } \\
\text { OF THS PAGE } \\
\text { Unclassified }\end{array}$ & $\begin{array}{l}\text { 19. SECURITY CLASSIFICATION } \\
\text { OF ABSTRACT } \\
\text { Unclassified }\end{array}$ & \\
\hline NSN 7540-01-280-5500 & & & $\begin{array}{l}\text { andard Form } 298 \text { (Rev. 2-89) } \\
\text { scribed by ANSI Std. Z39-18 } \\
3-102\end{array}$ \\
\hline
\end{tabular}

